\title{
The Ozone treatment for Elimination of toxic waste - An alternate for preservation of goat skins and enhancement of bleaching property of starch
}

\author{
V.Lakshminaryanan ${ }^{1}$, Gokul sidarth Thirunavukkarasu ${ }^{2}$, P.A.Balakrishnan ${ }^{3}$ \\ ${ }^{1}$ Associate Professor, Dr.Mahalingam College of Engineering and Technology, Pollachi, India. \\ vlnaarayan@gmail.com \\ ${ }^{2}$ Student, Deakin University, Waurnponds, Australia \\ gthiruna@deakin.edu.aus \\ ${ }^{3}$ Professor , Sri Ranganathar Institute Engineering and Technology, Coimbatore-641110, TN, India \\ Pabala52@gmail.com
}

\begin{abstract}
In line with the staggering number of about 14 percent of India's GDP relying on the food processing industry. Our area of research aims at exploring the wide spread applications of the use of ozone a chemical compound that has the property of being a strong oxidant along with its potent capabilities of being a disinfecting agent in the food processing industry. Specifically focusing on the implication of the ozonized based processing techniques on the food and animal related processed products which include goat skin and manufacturing of starch. During the phase of the research we compared the impacts, advantages on using Ozone based processing technique over the existing methods like salt curing, and starch manufacturing from tapioca starch involves washing,peeling, rasping, screening, packaging, drying, pulverization, dewatering and dry screening. Ozonised skins kept exposed to atmospheric air were more impervious to microbial activity is in existence. This opens up the likelihood of applying Ozonisation innovation to protect goatskins so as to take out earth unsafe salt curing. And improving the whiteness property of sago starch without creating any harmful by products using Ozonisation based techniques.
\end{abstract}

Key words: Ozonisation; Anti-microbial action, preservation, Starch, Whiteness, pH.

\section{INTRODUCTION}

This research entitles the main focus of the application of the corona discharge methods used for ozone generation in line to the below mentioned objectives of the goat skin processing and sago starch processing. In the process of experimenting its efficiency we also compare the performance index with the widely used in house practices.

Salt curing strategy for preservation of goat skin is sparing, moderately solid and can be expert without refined gear. Salt curing, nonetheless, additionally has restrictions. These incorporate expanded profluent contamination for the leather expert and skin processor, the destructive way of concentrated salt arrangements, the challenges related with transportation salted stows away, and a lessened region yield.

A cost-effective and reliable alternative to salt for the preservation of skins has already been a research objective of the leather industry for many decades. Many non-salt chemical and physical methods of preservation have been suggested but none have achieved widespread commercial use. Bout curing is economical, relatively reliable and can be accomplished without complex equipment. Brine healing, however, also offers limitations. These kinds of include increased effluent polluting of the environment for the tanner and skin processor, the corrosive nature of concentrated sodium solutions, the difficulties associated with shipping salted covers, and a reduced area yield. Ozone is a powerful disinfecting agent; it reacts with the cellular wall of the germs and degrades.

Sago starch and its finished products are being used as food, animal feed and as raw material for several commercial products. Starch is considered as the cheapest supply of Carbohydrates among the cereals, tubers and root crops and it is a software program diet in many components of Africa, South America \& Asia. India any of the leading countries in starch production. Manufacturing process of starch from tapioca starch involves peeling, washing, rasping, screening, dewatering, drying, pulverization, dry screening and packaging. In order to improve the whiteness property of the starch several chemicals were added during the manufacturing process of the starch. The particular residue of this chemicals present in the starch can cause several side outcomes in human beings.

\section{CONVENTIONAL PRESERVATION METHODS OF SKIN}

\section{Green Salting}

Green salting is the term connected to the act of "curing" wherein salt is spread over the tissue side of the crisply excoriated stow away and the characteristic procedure of arrangement and dissemination is permitted to continue. In the simplicity of cows stow away and incidentally kip skins, a coarsely crystalline salt is utilized, which is spread physically by method for a scoop in an equal proposition.

\section{Brining}

The utilization of salt arrangement as a preparatory or starting safeguarding treatment for dairy cattle covers up has been standard practice in South American meat pressing plants for a long time. 


\section{Pickling}

The expression "pickling" for the most part alludes to the strategy for protecting dewooled sheepskins by drenching them for a given period in around half-immersed saline solution containing a low rate of corrosive, for example, sulfuric. By watching reasonable safety measures to keep up cool temperature $s$ and to forestall dissipation, such skins can be held for a long time without clear weakening.

The procedure is by and large looked upon as one of protection including a move in the $\mathrm{pH}$ estimation of the stock from the range, which is ideal for most proteolytic chemical activity to one of insignificant impact. The main capacity of the brackish water is to counteract intemperate hydration of the stock supported by the low $\mathrm{pH}$.

\section{Drying}

Conservation of covers up and skins through expulsion of their regular dampness content has for quite some time been a practice in those terrains where salt is an extravagance thing. The item is frequently of low quality because of climate conditions not helpful for acceptable drying up by unconstrained vanishing. Skins are of preferred quality over shrouds as a result of their distinction in thickness, or all the more absolutely, because of the more prominent surface accessible per pound of dampness to be dissipated.

Such air-dried items likewise are ease back to retain when wet back at tannery and adept to do as such exceptionally nonconsistently. David G.Bailey (2003) (12) have found that the expansion of sodium polysulfide to the splash water rushes the procedure and lessens the frequency of "dry" spots.

\section{Expansion of Supplementary Agents}

Immersed salt arrangements don't have bactericidal properties and are bacteriostatic just under positive conditions. Hence added substances having germicidal impact are frequently utilized to enhance the resistance of salt-cured covers up and skins to debasement, particularly when refrigeration is not accessible or is excessively costly.

Among the added substances discovering acknowledgment are anhydrous sodium carbonate, borax in addition to boric corrosive, sodium silicofluoride, sodium sulfate, and sodium hypochlorite. Notwithstanding these Stuart and Frey (1933) $\{13\}$ have found in lab tests that paranitrophenol, sodium trichlorophenate and beta-naphthol yield promising outcomes when present in the curing salt at levels of .1 to 0.5 percent.

\section{MATERIAL AND METHOD}

From fresh goatskins, twelve samples of three square inches were cut. Test specimens were removed methodically from the skin. Samples cut from the skin were alternately marked either for experiment or for control. The ozonised samples were tested for bacterial count and all the samples were tested for growth rate every day.

Silent electric discharge type ozone generator was used with industrial oxygen as feed gas. The skin samples were placed in the cylindrical glass chamber. Experimental skin pairs were exposed to ozone at $2 \mathrm{~g} / \mathrm{hr}$ for a period of 2 hours max by holding the skins on metal stand inside the glass column reactor as shown in Fig 1.

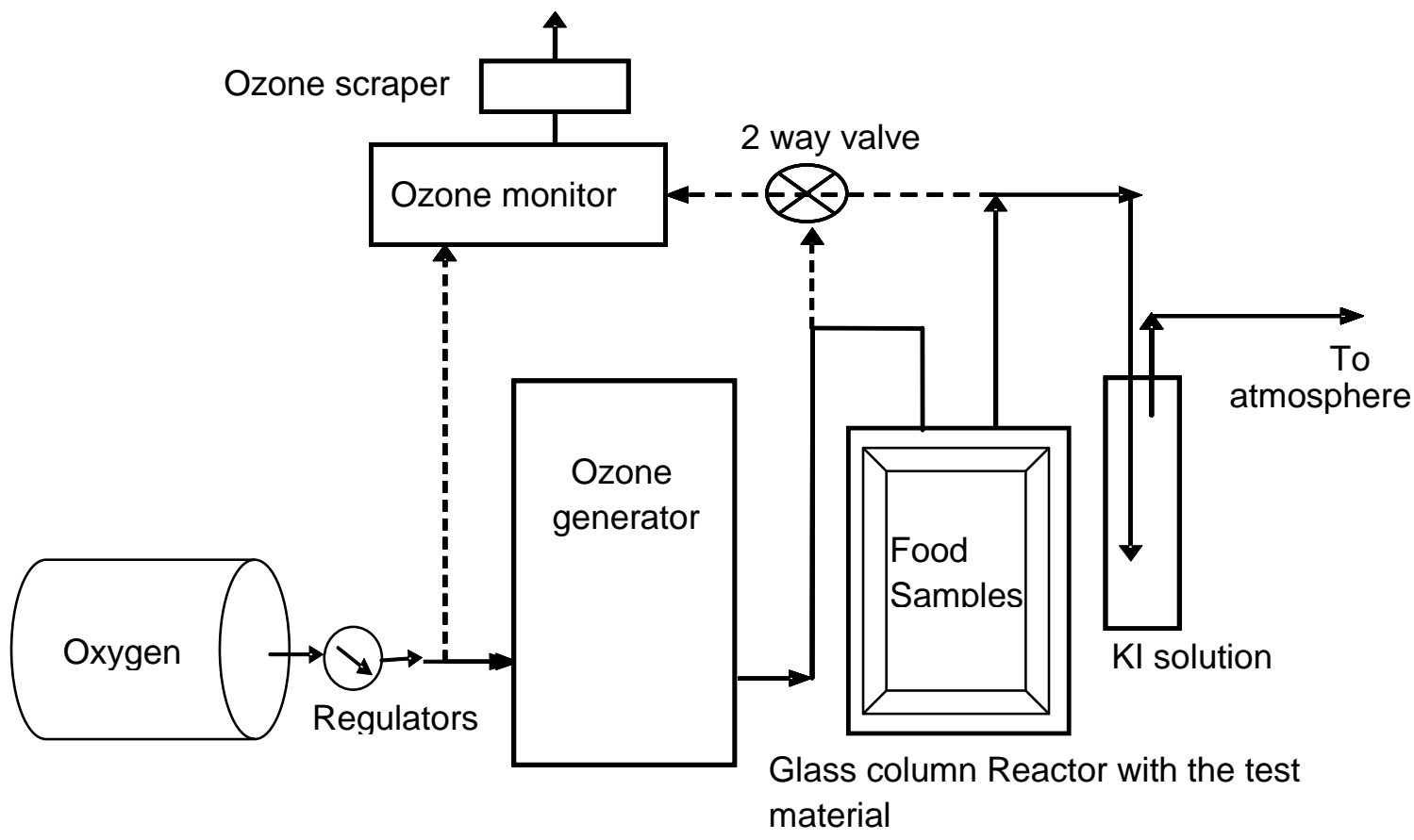

Fig 1: Experimental setup of Ozone reactor used for food processing 


\section{Bacterial determination}

The pour plate method was utilized to decide the quantity of microorganisms $/ \mathrm{mL}$ or organisms/gram in an example. Types of gear utilized are $10 \mathrm{~mL}$ sterile Plate, Count Agar (PCA), softened and cooled to 45oC, T1000 and T100 micropipettes, and sterile petri plates. The cut skin tests were weighed and unsettled with $100 \mathrm{ml}$ sterile refined water. The washes were weakened to the required weakening under sterile conditions. Suitable weakening were plated with Plate Count Agar after $0.01 \mathrm{~mL}$ of the last weakening was immunized into the petri plates. Plates were secured and blended altogether by twirling and tilting the plates. The plates were put on a level surface undisturbed for around 10 minutes to permit the agar to totally gel. Plates were tallied following 2 days brooding at room temperature.

\section{Spectrometric analysis}

The bisected membrane samples were weighed and disturbed with $100 \mathrm{~mL}$ sterile unadulterated water. $0.01 \mathrm{~mL}$ with this solution was added to $10 \mathrm{~mL}$ of Nutrient Broth at sterile condition. This kind of was shaken well and the optical density of the solution was tested with plain Nutrient Broth as the standard. This kind of optical density was indication of the microorganism present on the skin and data on consecutive days and nights indicate the growth rate of microorganisms per day.

\section{Bacterial counts}

Unexposed skin contained an average of $1 \times 104$ organisms per gram. Microbial densities on ozonised samples were measured after ozonisation. The results indicate that ozonisation is as effective as salting in retarding microbes growth at various coverage times. Thus the tolerance dosage has been achieved in the initial 50 percent an hour though increased exposure time results in sustained microbial retardation.

\section{Putrefaction}

Every one of the samples were inspected every day for hair-slip and other indicators of putrefaction. These observations are portrayed in Fig. 2 and it was observed that the ozonised samples positioned in a sealed tote got putrefied. It was due to the action of anaerobic bacteria that happen to be much more active than aerobic bacteria.

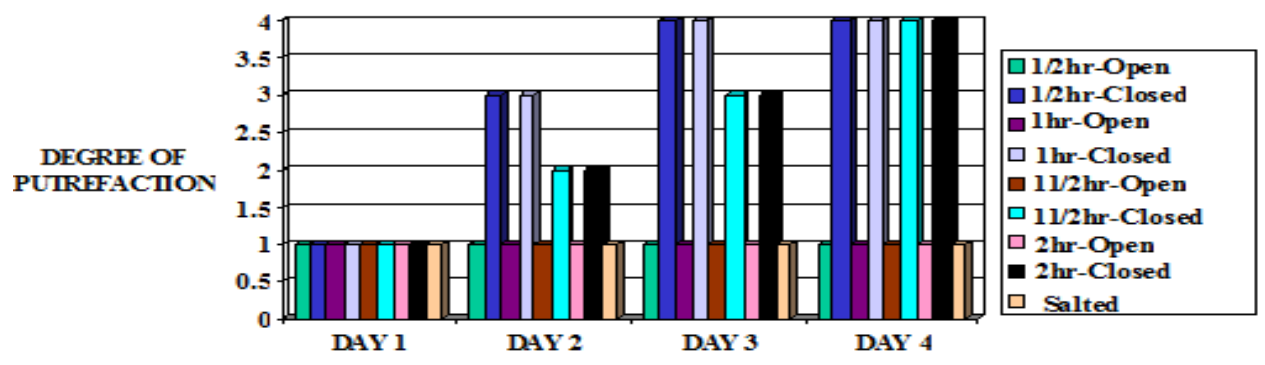

Fig 2:Putrefaction Vs Time

\section{RESULTS AND DISCUSSION}

\section{Spectrometric data}

After detailed analysis from the data obtained, it was graphically represented in the form of graphs as shown in the Fig.3-6 that explains various ozone experiments and its results and Fig.7 for control response of the system. It is clear from the observation that the growth of microorganisms in ozonised environment follows the same pattern as that in case of salted samples. This clearly indicates the effectiveness of ozonisation in this particular application.

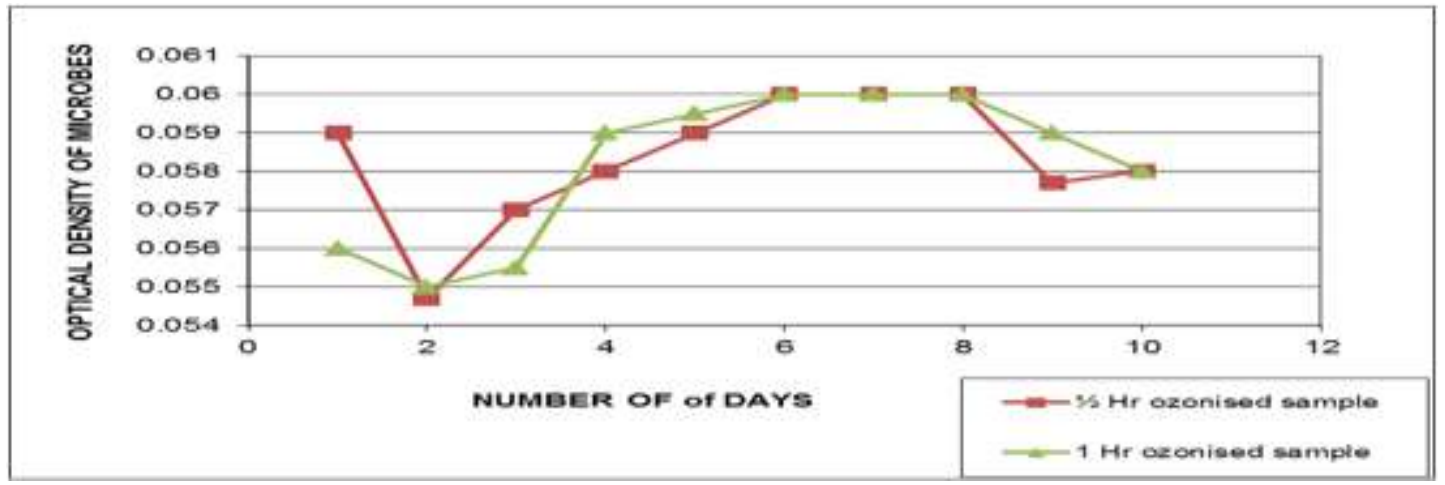

Fig 3: Escalation graph curve for two sample exposed to environment(A1\& A2) 


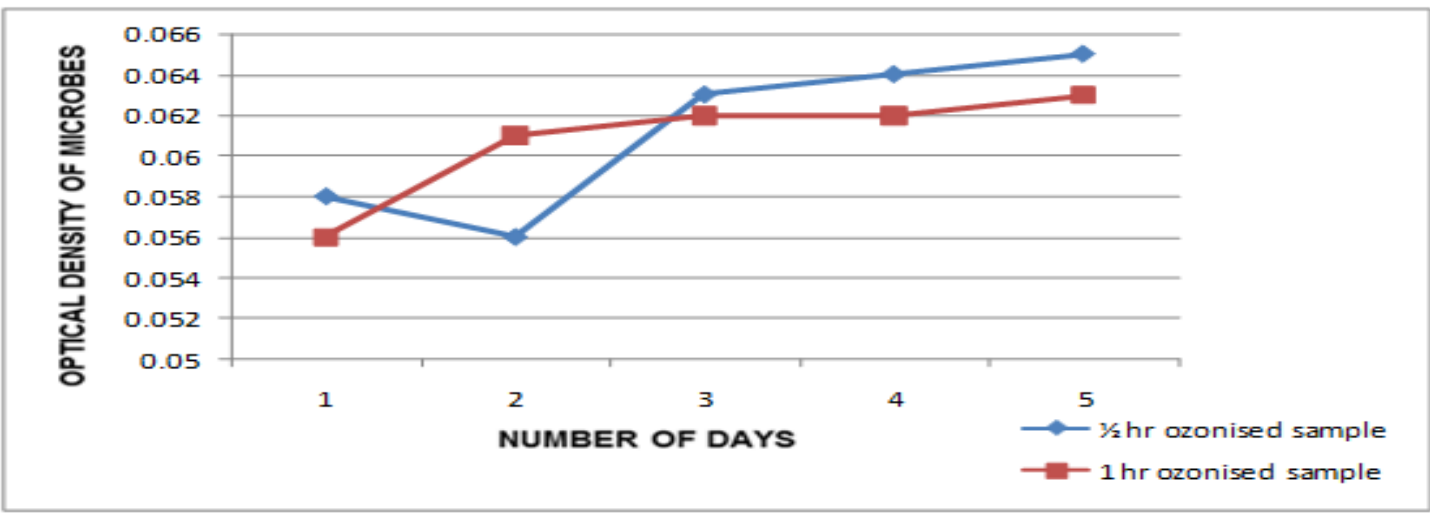

Fig 4: Escalation graph curve for two sample placed in a Sealed bag (B1\&B2)

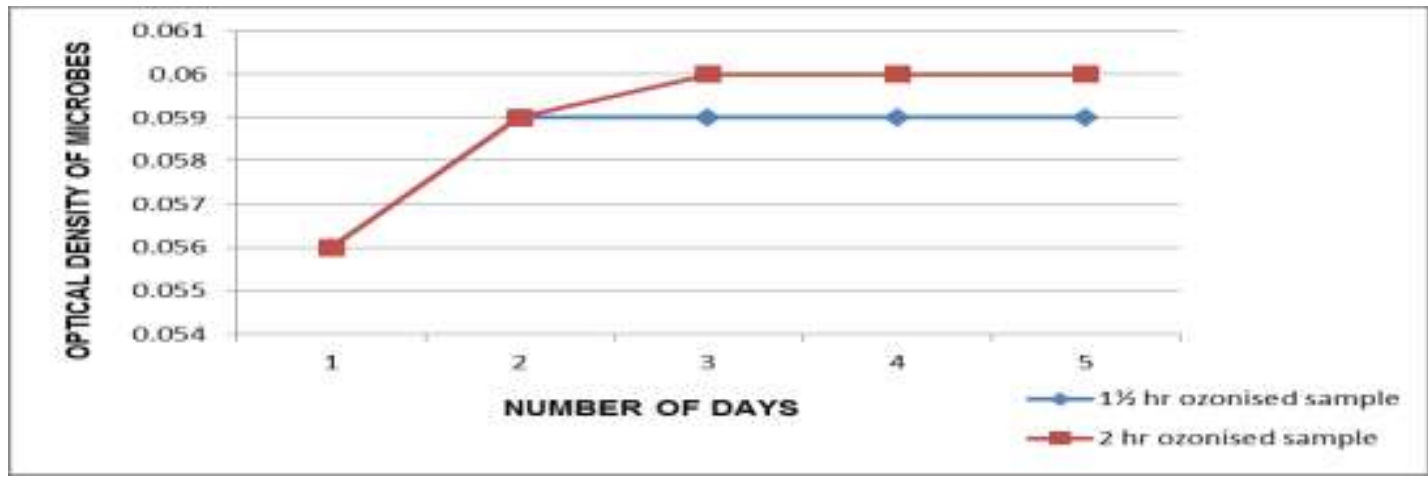

Fig 5:Escalation graph curve for two samples exposed to environment (A3 \& A4)

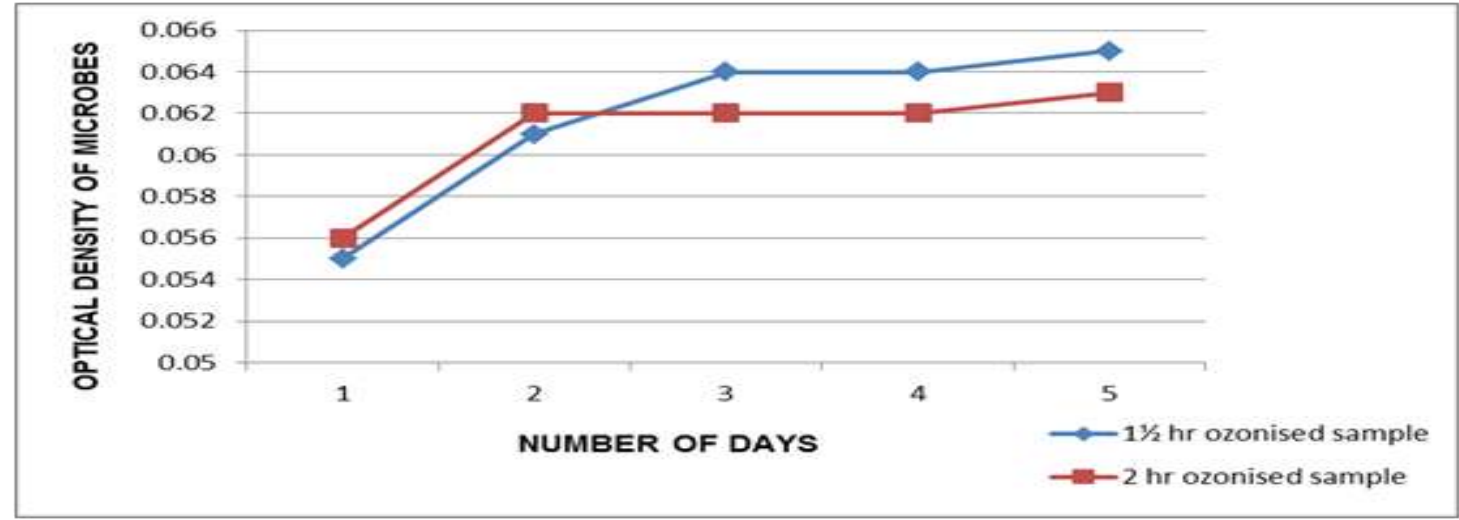

Fig 6:Escalation graph curve for two samples placed in a Sealed bag (B3 \&B4)

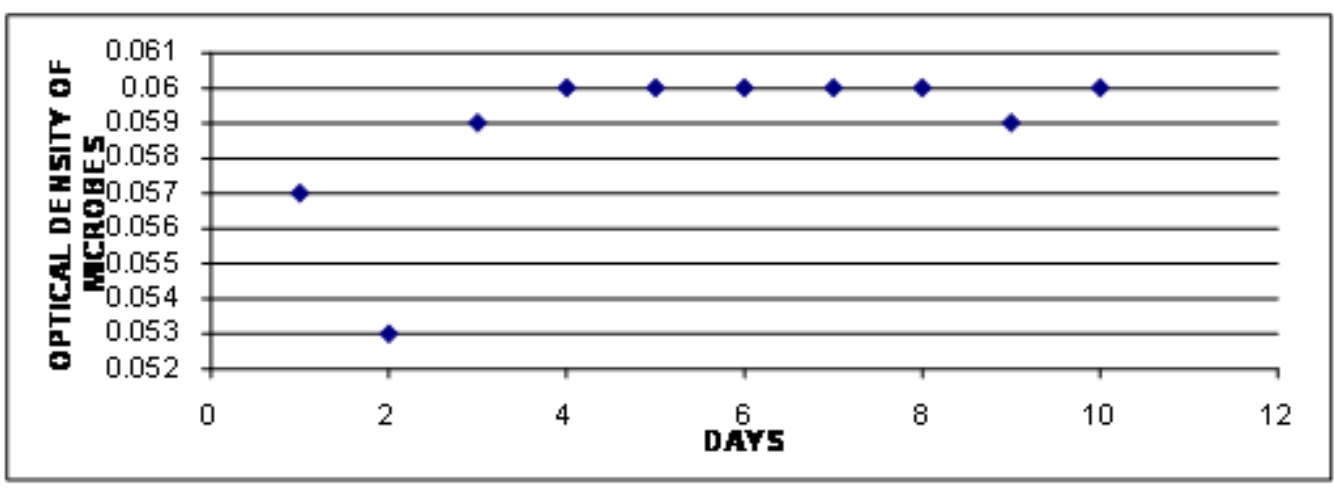

Fig 7:Escalation graph curve for control sample(c) - salted

The test samples were compared with the control sample. From the above graphs it can be seen that ozonised samples kept in the open exhibit behavior similar to that of salted samples. Thus raw skin ozonated and kept in open was as effective as salting. The results of the observation where that the OD value of the sample was $\geq 0.062$, which in turn starts 
the purification of the skin. The sample results kept in the sealed bag where predominant for us to prove that the growth curves of the exposed specimens prove that the growth of anaerobic microorganisms inside the sealed bag in the oxygendepleted environment.

\section{OZONE IN BLEACHING APPLICATION}

There are various application zones of ozone in the business, for example, dying, nourishment surface cleanliness (5), sanitation of sustenance plant gear, squander water treatment (4) and bringing down natural oxygen request (BOD) and compound oxygen request (COD) of sustenance plant squander. Just few looks into were made with deference the dying properties of ozone.

A portion of the utilizations of ozone identified with blanching are as per the following.

1. It is utilized for fading cotton textures (1),

2. It is utilized as a decent lighting up specialist for blanching Kraft mash (2).

3. It is utilized for fading sunflower squander oil (3)

Not very many applications are accessible as for the fading of sustenance items. We chiefly centered around fading of starch which is one of the real nourishment materials utilized by Indians.

At present part of chemicals were utilized as a part of request to expand the whiteness of the starch. These chemicals added to the starch stay as a deposit and cause a few symptoms in people. With a specific end goal to maintain a strategic distance from these chemicals, we made an endeavor to blanch starch by utilizing ozone which won't create any deposit.

\section{WHITENING PROPERTY}

The $\mathrm{pH}$ of the diluted starch solution indicated that in addition to the preservation properties that the ozone possesses the whitening property of the ozone would help us in the process of starch extraction from the above-mentioned methods. The following time graph clearly illustrates that the ozone treatment enhanced the property of color with minimal change in the ph level. This application overruled the diverse impacts of the adverse effects of human's involved in the process of starch extraction, which make this method a more simplified, and a sustainable solution.

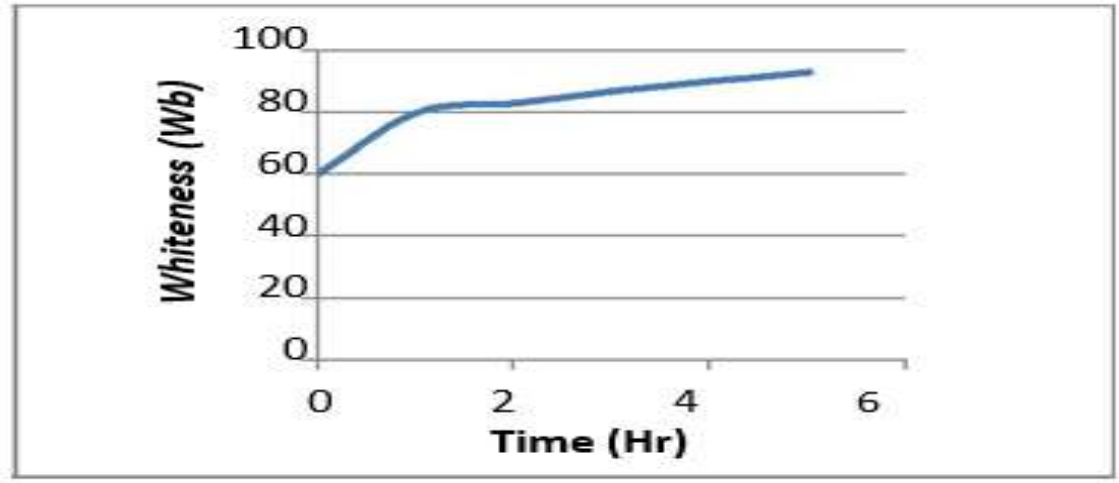

Fig 8:Whiteness Vs Time Graph in starch extraction

\section{CONCLUSIONS}

The effectiveness of ozonisation in the applications of the Goat skin treatment and the eco-friendly starch extraction proves that the corona based setup used for ozone synthesis has many applications. It was observed from the test cases that the anaerobic microorganism growth was significant in the sealed bags which proved that the ozone treatment over the goat skin enhances the life cycle of the goat skin and prevents communication of disease. In addition to this the research carried out of the starch extraction proves its value by eliminating the involvement of humans exposed hazardous environment meeting the demand of enhanced whiteness with lowered ph ratting. Ozone concentration analysis at the inlet as well as outlet of the corona discharge chamber was measured to find out the amount of ozone utilized for the process. This acted as a base of our future research works of designing a better ozone chamber using a novel ozonisation method.

\section{REFERENCES}

1. Seher D. Perincek, Kerim Duran, Aysegul E. Korlu \& İbrahim M. Bahtiyari "An Investigation in the Use of Ozone Gas in the Bleaching of Cotton Fabrics" Ozone: Science \& Engineering: The Journal of the International Ozone Association Volume 29, Issue 5, 2007 page 325 - 333

2. Carre G, Wennerstrom M. (2005): "Ozone bleaching" - An established technology, IPBC, Stockholm, Sweden, 144-149. 
3. Sivasakthivel.s, Nandini.N, “ Bleaching Of Sunflower Waste Oil By Absorption On Activated Carbon And Improved By Ozonisation" American international journal in research in science, technology, engineering \& Mathematics.

4. Keisuke Ikehata, Mohamed Gamal El-Din \& Shane A Snyder "Ozonation and Advanced Oxidation Treatment of Emerging Organic Pollutants in Water and Wastewater" Ozone: Science \& Engineering: The Journal of the International Ozone Association (2008)

5. Ravi Shankar, Kaushik, Shayeeb Ahmad Bhat, "Food Processing and preservation by Ozonation" International Journal of Science, Engineering and Technology (2014)

6. Fetner, R.H. and R.S. Ingols, "A comparison of the activity of ozone and chlorine against E. coli at $1^{\circ} \mathrm{C}$ ", Journal of General Microbiology, 15:381-385 (1956)

7. Foegeding, P.M. "Ozone inactivation of Bacillus and Clostridium spore populations and the importance of the spore coat to resistance", Food Microbiology, 2:123-134 (1985).

8. Ishizaki, K., N. Shinriki, and H. Matsuyama, "Inactivation of Bacillus spores by gaseous ozone", Journal of Applied Microbiology, 60:67-72 (1986)

9. Restaino, L., E.W. Frampton, J.B. Hemphill, and P. Palnikar, "Efficacy of ozonated water against various foodrelated microorganisms", Applied and Environmental Microbiology, 61(9):3471-3475 (1995).

10. Khadre, M.A. and A.E. Yousef, "Sporicidal action of ozone and hydrogen peroxide: A comparative study", International Journal of Food Microbiology, 71(2-3):131-138 (2001)

11. Guzel-Seydim, Z.B., P.I. Bever, and A.K. Greene, "Efficacy of ozone to reduce bacterial populations in the presence of food components", Journal of Food Microbiology, 21: 474-479 (2004)

12. David G. Bailey," Preservation of Hides And Skins “, Journal of American leather chemist association, 98: 308$319(2003)$

13. Stuart, L. S., Frey, R. W., and James, Lawrence H. "Microbiological studies of salt in relation to the reddening of salted hides", U. S. D. A. Tech. Bull. 383 (1933).

14. Sivakumar, V., et al. "Use of Ozone as A Disinfectant for Raw Animal Skins-Application as Short-Term Preservation in Leather Making." Ozone: Science \& Engineering $32.6 \quad$ (2010): 449-455.

\section{Author' biography with Photo}

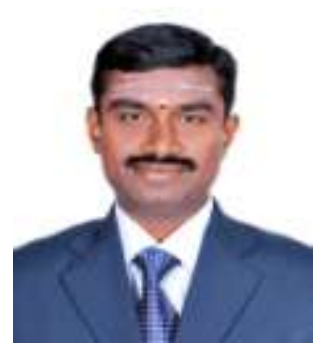

Dr.V.Lakshminarayanan, Associate Professor in EIE Dept., He is an Electrical and Electronics Engineer from the Govt. College of Technology, Coimbatore. He holds his Master's degree in Applied Electronics, from Anna University, Chennai through Maharaja Engineering College, Avinashi and he completed his doctoral degree from Anna University-Chennai in 2013. He published 7 papers in International Journals , 2 International Conferences and more than 15 national conferences.

He joined the stream of Faculty of Electrical and Electronics Engineering in the year 2004 and has more than 16 years of teaching and 8 years of Industrial experience. Under his guidance, 14 batches of UG students have obtained various projects and 9 PG students have done their thesis in electrical control equipments, embedded systems, Communication and Industrial automation areas till date. His field of interest and research are Industrial Electronics, Industrial Chemistry (Study on Ozone generation), Industrial Data Communication Network and High performance communication engineering. He is a Member of The Indian Society for Technical Education and served as Secretary for ISTE-MCET Chapter for four year, he is also a member of various Professional bodies like ,ISA,CII, ISOI etc.

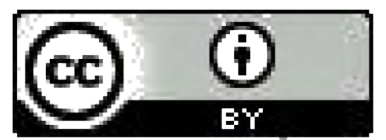

This work is licensed under a Creative Commons Attribution 4.0 International License. 